\title{
New directions in socioscientific issues research
}

\author{
Dana L. Zeidler ${ }^{1 *}$, Benjamin C. Herman ${ }^{2}$ and Troy D. Sadler ${ }^{3}$
}

\begin{abstract}
The socioscientific issues framework has proven to have a significant impact over the last two decades on many areas related to the development of functional scientific literacy in students. In this article, we summarize and synthesize recent trends in socioscientific issues research that impact both disciplinary and interdisciplinary science education research. These trends represent science-in-context investigations that we propose are advanced by three broad and interrelated areas of research including: 1) Socioscientific Issues and the Central Role of Socioscientific Reasoning; 2) Socioscientific Issues and the Primacy of Socioscientific Perspective Taking; and, 3) Socioscientific Issues and the Importance of Informal and Place-Based Contexts. We discuss the most recent research in those areas and explore the educational significance these new trends.
\end{abstract}

Keywords: Socioscientific issues, Socioscientific reasoning, Socioscientific perspective taking, Informal science education

\section{Introduction}

The role of Socioscientific Issues (SSI) has proven to be a major impetus in the promotion of scientific literacy within the science education community over the last two decades. The SSI movement has drawn from a wide swath of interrelated scholarship (e.g., epistemological maturation, sociomoral discourse, emotive reasoning, character education, nature of science and argumentation) that uniquely positions it as a sociocultural progressive framework serving as a counterpoint (or a complement) to recent STEM initiatives as commonly conceived and practiced in academia. That sociocultural perspectives as those advocated in the SSI framework has to be at best, inferred and not explicitly addressed by initiatives such as A Framework for K-12 Science Education (National Research Council, 2012) or the Next Generation Science Standards (2013) in the US, suggests to us that other global initiatives not look to the US as the "Gold Standard" for progressive frameworks (Zeidler, 2014; Zeidler, 2016; Zeidler et al., 2016). In the absence of explicit sociocultural approaches to science education, these past (and even current) trends have, at times, produced tensions

\footnotetext{
* Correspondence: Zeidler@usf.edu

'Department of Teacher Education, College of Education, University of South Florida, Tampa, Florida, USA

Full list of author information is available at the end of the article
}

between more traditional essentialist expectations and specializations found in discrete discipline "silos" of science and the kind of normative discourses and cross curricular connections typically encouraged in progressivist pedagogy (Bossér \& Lindahl, 2019; Elgström \& Hellstenius, 2011; Lindahl, Folkesson, \& Zeidler, 2019).

In more traditional approaches to science education knowledge is generally decontextualized, while in the progressivist tradition, the kind of discourse and knowledge formation found is the result of students' deliberative conversations about authentic problems that allows them to become active participants in democratic decisionmaking. In the latter case, both the pedagogy and curriculum necessarily becomes contextualized because the type of sociocultural framing that resides in SSI is, de facto, connected to the quality of personal, community and global issues. Accordingly, the kind of reasoning found to be productive in evaluating the quality of anthropocentric and ecocentric factors that SSI discourse requires, are important components in forming scientific identities (Simonneaux \& Simonneaux, 2009). The formation of scientific identities is promoted when students connect a feature of personal meaningfulness to both the human condition, as well as to the context of scientific thought, inquiry and discovery. We will find shortly, that Sadler, Barab, and Scott (2007) have termed socioscientific 
reasoning as a special suite of skills necessary to engage students in the evaluation of contextualized SSI.

Since SSI education is aimed at attaining "functional scientific literacy," it entails the facilitation of strategies that enable students to make informed decisions, analyze, synthesize and evaluate varied sources of data and information, use moral reasoning to attend sensibly to ethical issues, and understand the complexity of connections inherent within contextualized science learning. Zeidler (2014) has argued that SSI education ideally should, to the extent possible:

- Utilize personally relevant, controversial, and illstructured problems that require scientific, evidence-based reasoning to inform decisions about such topics.

- Employ the use of scientific topics with social ramifications that require students to engage in dialogue, discussion, debate, and argumentation.

- Integrate implicit and/or explicit ethical components that require some degree of moral reasoning.

- Emphasize the formation of virtue and character as long-range pedagogical goals (p. 699).

An umbrella term for this type educative experience is called science in context (SinC) with the goal of actively promoting the well-being of living things that are in balance with the non-living world (Bencze et al., in press). The recognition of balancing anthropocentric and ecocentric factors is further recognized in the contextualized place-based education research found in the work of Herman, Owens, Oertli, Zangori, and Newton (2019) and related ecojustice approaches to environmental education (Herman, Sadler, Zeidler, and Newton (2018).

The SinC approaches reported above have been built on a foundation of past research. We explore how that foundation has resulted in new directions in SSI research in more detail below. In doing so, we aim to create a bridge that connects essential areas culled from past research with promising new explorations that will likely shape SSI research in years to come. We identify and discuss below three SinC themes in an effort to highlight new directions in SSI research. These include: 1) SSI and the Central Role of Socioscientific Reasoning; 2) SSI and the Primacy of Socioscientific Perspective Taking; and, 3) SSI and the Importance of Informal and Place-Based Contexts.

\section{SSI and the central role of Socioscientific reasoning}

A critical question for science educators interested in advancing the SSI research agenda is what do students learn through engagement in SSI based learning experiences. From the outset of the SSI movement, proponents suggested that SSI based instruction (and related approaches) should support student learning of science content (Zeidler, 2003). This seemed to be a necessary condition for using SSI in science classrooms, but learning science concepts alone has never been the primary focus of the SSI movement. Using SSI as a means of supporting student learning about the nature of science (NOS) was one of the earliest foci for SSI research (e.g., Zeidler, Walker, Ackett, \& Simmons, 2002). As SSI gained traction in the field, researchers began exploring a broader range of potential learning outcomes associated with opportunities to negotiate SSI. These outcomes included ethical sensitivity (Fowler, Zeidler, \& Sadler, 2009), argumentation (Venville \& Dawson, 2010), and reflective judgement (Zeidler, Sadler, Applebaum, \& Callahan, 2009). While all of these measures (science content, NOS, ethical sensitivity, argumentation, and reflective judgement) make sense as learning targets for SSI instruction, none of them are uniquely situated with respect to SSI.

Sadler et al. (2007) argued that high quality SSI learning experiences should do more than help students understand more science, become more ethically sensitive, or demonstrate better argumentation practices. SSI learning experiences should help students become better at dealing with complex issues like SSI. For example, learning science in the context of climate change should do more than help students understand the science of climate, these experiences should help students become better prepared to engage in decision-making and position taking in the context of climate change. Furthermore, an SSI learning experience related to climate change should also help students be better prepared to engage in decision-making and position taking relative to SSI other than climate change. A challenge to this line of thinking was a lack of conceptual or measurement tools to explore the extent to which SSI education was actually leading to these goals.

In order to address this challenge, Sadler et al. (2007) proposed socioscientific reasoning (SSR) as a construct to capture the reasoning practices associated with negotiation and resolution of SSI. The original articulation of SSR included four dimensions: complexity, inquiry, perspective taking, and skepticism. Subsequent work resulted in the addition of affordances and limitations of science as a fifth dimension. Each of the dimensions is described below.

- Complexity: the ability to perceive and reason through the complexity inherent to SSI.

- Inquiry: the ability to recognize information that is not available regarding an issue as well as the ability to consider ways in which that information may be generated. 
- Perspective-taking: the ability to analyze an issue and potential solutions from the perspectives of different stakeholders.

- Skepticism: the ability to identify potential sources of bias that may influence information or the presentation of information about an issue or potential solutions.

- Affordances \& Limitations of Science: the ability to determine how scientific knowledge and processes may contribute to the resolution of an SSI and to recognize dimensions of the issue that cannot be addressed by science.

Initial attempts to document learner SSR competencies were made through in-depth interviews in which students read and responded to narrative scenarios about an SSI (Sadler et al., 2009). This research helped to inform attempts to operationalize the construct, but the interview format was not practical for interventionoriented studies that require pre/post testing and large sample sizes. Follow-up research designed to explore the impacts of an SSI learning experience on students' SSR competencies employed scenarios like the initial research, but student responses were collected through open-ended surveys (Sadler, Klosterman, \& Topcu, 2011). This study focused on student learning in the context of a two-week, SSI-based climate change unit. Whereas students showed learning gains for science content, they did not demonstrate statistically significant gains in SSR. The researchers suggested that the longerterm engagement with SSI learning experiences was likely necessary for detectable improvements to SSR.

Based on these findings, Kinslow, Sadler, and Nguyen (2019) tested SSR learning associated with a six-week intervention focused on a related set of environmental SSI. Pre/post testing of students in this setting revealed statistically significant increases with medium to large effect sizes in SSR. As in the previous work, the SSR assessments were based on scenarios with open-ended questions. Student artifacts (e.g., writing assignments and journal entries) collected throughout the course were used to triangulate the increases documented through quantitative analyses. However, a limitation in this study was the similarity between the issues featured within the class and the scenario used for the assessment. The study provided evidence that students can make improvements in their SSR, but these data did not necessarily provide evidence of learners' being able to transfer SSR developed in the context of one issue to a dissimilar issue.

The research team sought to address this limitation through another intervention study in which the contexts for instruction and assessment featured different issues (Kinslow, 2018). In this study, the researchers partnered with a science teacher and a social studies teacher to design a high school course organized around SSI. The five SSR competencies described above were featured in the course design, and students had multiple opportunities to practice their use of these competencies as they negotiated numerous SSI related to climate change, genetic engineering, and water resources. Pre/ post analyses of SSR scores suggested statistically significant improvements with medium effect sizes for all five competencies. This is an encouraging result, which indicates that SSI instruction, when done well, can in fact support development of sophisticated reasoning specific to the complex dimensions of SSI.

While this progression of studies provides evidence that SSR can be reliably measured and that SSI instruction can support SSR learning, much remains to explore regarding the construct. It appears that limited engagement learning experiences such as a single unit of instruction are not enough to support detectable SSR learning gains but that learning experiences over the course of a semester (18 weeks) can support gains in SSR. Most science educators cannot feature SSI instruction consistently over an entire semester, so further explorations regarding how much SSI learning is required to show SSR gains would be helpful. There are also several important SSR measurement questions that remain unanswered. Romine, Sadler, and Kinslow (2017) developed a multiple-choice version of an SSR assessment (the Quantitative Assessment of Socio-Scientific Reasoning-QuASSR). This instrument has good psychometric qualities and makes large scale assessments of SSR relatively easy to conduct; however, concerns remain regarding the validity of using forced choice items to estimate complex SSR competencies. A different solution to the challenge of assessing SSR with large samples is to use open-ended scenarios that require respondents to demonstrate their reasoning through writing and to assess these responses with computer automated scoring (CAS) models. Womack (2019) has begun an exploration of this solution with promising results indicating that CAS models can be developed for reliable scoring. As of now, a reliable CAS model only exists for one scenario so the applications of this solution are limited. However, advances to ways in which SSR is conceptualized and measured create new possibilities for incorporating SSR in science teaching and educational research.

\section{SSI and the primacy of Socioscientific perspective taking}

In attempting to unpack SSR, recent conceptual and empirical scholarship has focused on the what is arguably the primal SSR construct that allows for the exercise of judgment in a manner that is, at once, caring and empathetic, (see Kahn \& Zeidler, 2016, 2017; 2019). To best 
understand its importance, it is instructive to follow a line of research that examined emotive reasoning as expressed in formal SSI contexts (Fowler et al., 2009; Sadler \& Zeidler, 2005). Cognitive and affective processes experienced when engaging in contentious and ethically challenging scientific issues characterize emotive reasoning. The ability to invoke elements of emotive reasoning such as, for example, righteous indignation, empathy, or moral sensitivity, is directly tied to the primacy of perspective taking. That is, perspective taking is a necessary but not sufficient condition for the exercise of mature moral judgment. While scholars have discussed the role of empathy relative to its importance in making ethical decisions (Batson, 2009; Hoffman, 2000, 2008), perspective taking has remained a "fuzzy" construct. We have argued that perspective taking is a multidimensional construct that transcends the artificial dichotomy of being thought of as a purely cognitive or affective construct, and entails blending elements of moral behavior, moral character, moral values, moral reasoning, moral emotion, moral identity, and metamoral characteristics (Berkowitz, 1997; Herman, Zeidler, \& Newton, 2018). Given that researchers have noted there has been a $40 \%$ decrease over the last four decades in perspective taking and empathetic concern for others among college students (Herman, Zeidler, \& Newton, 2018; Konrath, O’Brien, \& Hsing, 2011), this concern and the lack of preciseness in the construct has been the impetus of a new line of research.

Zeidler and Kahn (2014) have conceptually analyzed the task of employing perspective taking. It is important to keep in mind that the SSI framework uses argumentation, debate, discussion, and other forms of discourse as a means to engage thinking and reasoning processes, and to mirror the discourse practices used in real life in the advancement of intellectual and scientific knowledge. It is equally important to remember that, as educators, we try to provide a forum where the focus is on tolerance, mutual respect, and moral sensitivity. For this to happen, perspective taking is a keystone that supports much of SSR and the development of empathy, moral sensitivity, and related constructs.

Past research has shown that teaching within the context of socioscientific issues can increase students' moral sensitivity, thus contributing to overall moral development (Fowler et al., 2009), but understanding how to leverage this important finding in classroom practice requires a deeper understanding of the underlying mechanisms involved. We have found that one's dominant culture is a double-edged sword, serving both as an ethnocentric lens to solidify group identity as well as a filter that sifts out dissonant values that may run counter to one's core beliefs. Thus, in order for science teacher educators to foster SSR and functional scientific literacy, examining perspective taking at the level of pedagogical implementation is quite important.

Kahn and Zeidler (2016, p. 263) have synthesized a broad working definition of perspective taking as "one's ability to recognize and consider the diverse cognitive and emotional viewpoints of others within SSI." This notion was not arbitrary and drew from sociocultural and developmental literature (e.g., Martin, Sokol, \& Elfers, 2008; Selman, 1971, 1977) with a focus on educational practice. Accordingly, Kahn \& Zeidler have argued that in order to facilitate students' ability to consider multiple perspectives, we need to conceptually distinguish among Position - where one stands on an issue; Orientation - how one approaches an issue in relation to others; and Perspective - how one perceives and interprets an issue. The distinctions are pedagogically important because as students engage in SSI discussions, they may do so through different orientations, yet arrive at the same position all while holding differing perspectives from one another. It is also quite possible that students hold diverse positions while sharing related orientations and/or perspectives. Therefore, the SSI experience is best utilized when teachers can help students to understand through the exchange of ideas how the formulation of perspectives may come about.

Kahn and Zeidler (2019) further applied a systematic conceptual analysis of perspective taking to support SSR in SSI contexts, arguing that in order to "take" another's perspective, there were three necessary (and sufficient) conditions that needed to be met. First, there needed to be some level of engagement on the part of students. In the context of SSI, there needs to be a degree of personal, community or global significance that is relevant to the virtues a student holds firm. Second, an etic to emic shift whereby the perspective taker can move from their outsider perspective to the perspective of the "other" by exercising empathy - the ability to echo the other's perspective, while ideally, in their presence. Third, the necessity of a Moral Context in which the issue is embedded that necessitates the consideration of ethical principles and the exercise of moral reasoning. It is this third condition, the presence of a moral context, that distinguishes perspective taking in general, which requires only a neutral psychological shift, to one that is embedded within an ethical domain that requires the exercise of reflexive and reflective thought to determine the best combination of factors in the choice of moral justice and fairness: "One can connect with others and shift their viewpoint to appreciate others' perspectives for evil, or for no particular reason. What makes perspective taking appear to be a positive behavior is the assumption of a moral context condition" (Kahn \& Zeidler 2019, p. 621).

This work has led to the advancement of a novel construct referred to socioscientific perspective taking 
(SSPT) to reflect the kind of moral and contextualized reasoning bound up in the development of character and virtue within the SSI framework. It is important to note that a student need not change their perspective for perspective taking to occur, but they do need to shift their perspective to that of another, to understand how that perspective was formed in relation to their position and orientations concerning that issue. SSPT then, is intricately connected to scientific habits of minds that are simultaneously cognitive and affective in nature. In this regard, there exists a kind of duality in its application with respect to shifting between emic and etic perspectives. In its ideal form during the exercise of SSPT, the division between emic and etic viewpoints become blurred. Displaying open-mindedness, respecting others' arguments as well as employing sociocultural normative features that factor in the reciprocal interactions connecting culture and context aid in the formation of informed sociomoral judgment. The primacy of SSPT is central in that regard.

\section{SSI and the importance of informal and place- based contexts}

Efforts in SSI scholarship have been laudable to date with research attempting to provide more sophisticated and transparent accounts of how people engage SSI. Typically, SSI research and teaching has occurred primarily in formal learning contexts (e.g., classrooms) and through engagement with hypothetical scenarios and decisionmaking (i.e., willingness to act). This body of work has put forth important factors involved with SSI engagement, such as those that are more academic (e.g., science and NOS understanding) and those that are more affective (e.g., informal emotive reasoning). For instance, Zeidler, Herman, Ruzek, Linder, and Lin (2013) showed that while over 300 surveyed secondary students' epistemological reasoning demonstrated some congruence across cultures (e.g., Taiwan and US), statistically significant differences existed across cultures regarding their socioscientific decision-making, sophistication of scientific reasoning and epistemological beliefs when considering a medical resource allocation scenario. In a sense, this investigation provided some indication that variation in geographic place and culture influences how groups engage SSI. Lee et al. (2013) determined the impact of a 3-4 week genetic modification technology SSI classroom program on 132 ninth-grade students' character and values as global citizens. Through that instruction, the students became more sensitive to moral aspects of, and emotively concerned for those who are jeopardized because of, technological advancements. However, despite the extended classroom SSI learning the students struggled to emotively assume the perspectives of others suffering because of genetic modification issues and demonstrated a willingness to act within a community to resolve SSI. Herman (2015) investigated how 324 Floridian secondary marine science students perceptions about global warming science and sociocultural factors interactively influenced their willingness to mitigate global warming across five categories of actions each requiring varying levels of personal sacrifice. Notable findings from this study showed that the students' willingness to mitigate global warming was most consistently predicted by their perceptions about the validity of global warming scientists' claims followed by socioeconomic classification, NOS views and ethnicity. Furthermore, the students' willingness to mitigate global warming appeared to diminish with mitigating actions that required more sacrifice that is personal. Therefore, this research pointed to the need for better understanding about how and why science views are contextually operationalized in tandem with social, cultural and personal factors when people engage SSI. Despite this research highlighting the multifaceted cognitive and affective aspects of SSI engagement expressed in more formal classroom contexts, the way these factors influence SSI resolution and decision-making in particular real world contexts remains understudied.

Considering the aforementioned research, several deficits appear present with educational experiences occurring solely in formal learning contexts (i.e., classrooms) and research that entails hypothetical scenarios, issues and decisions. These deficits, when allowed to shape SSI instruction and research, appear quite bothersome as they inhibit efforts to help people become adept at becoming citizens who knowledgeably and civically engage SSI in their everyday lives (Herman, 2018). First, students may perceive such SSI learning experiences as detached from their lived experiences. Therefore, they may not see the significance and importance of resolving SSI at local and global scales. Second, through these experiences, students' learning will likely be impoverished because they will not be required to interact with the people and environments that are impacted by SSI. Therefore, they may be excluded deep and tangible scaffolded access to the science ideas, epistemological tools and resources, and practices and that scientists use to understand SSI (Sadler, 2009). Furthermore, students may also not be well positioned to demonstrate significant socio-cultural awareness, moral sensitivity, and compassion when contemplating perspectives and enacting decisions that constructively resolve SSI. Lastly, equating willingness to resolve SSI with how people will actually enact socioscientific decision-making under real-world conditions can be highly problematic (for examples see: Herman, 2015; Khishfe, 2012). The environmental behaviors field demonstrates that there is only a .45 correlation between stated pro-environmental intentions and enacted behaviors (Gifford \& Nilsson, 2014; Kormos \& Gifford, 2014). Similar findings have been 
shown with recent SSI research that showed only $44 \%$ of secondary students who claimed they would readily donate money to resolve environmental issues actually did so (Herman, 2018). Reconciling these deficits and learning how people respond to SSI as part of their lived experience should be among the foremost imperatives for SSI research.

More recent efforts in the SSI field (e.g., Herman, 2018; Herman, Zeidler, \& Newton, 2018; see also Kinslow et al., 2019 reviewed in this manuscript) have initiated efforts to begin to address such deficits. These studies do so by focusing on utilizing contexts that allow for large groups of students to be immersed in SSI contexts conducive to researching the often-interconnected factors involved in SSI engagement to include in their decisions.

Such initiatives seek to merge with approaches in the fields of place-based and informal science education (Gruenewald \& Smith, 2008; Semken \& Freeman, 2008; Sobel, 2004) and seek to leverage students' sense of place and attachment to the real "others" (people and the environment) who incur impacts from SSI and their resolution in order to promote ecological and cultural sustainability (Herman, Sadler, et al., 2018). This work subscribes from Semken and Freeman (2008, p. 1043-1044) who outline the importance of place-based education entailing:

1. experiential learning in and about local or regionally characteristic (i.e., authentically representative of the encompassing region) natural and social settings;

2. transdisciplinary and cross-cultural synthesis of place-related knowledge and pedagogy; and

3. service learning or other forms of community outreach.

From an SSI perspective, the situatedness and contextual features of the learning environment, including the cultural milieu involving the stakeholders impacted by SSI, are crucial components necessary for scaffolding students to more sophisticated ways of conceptualizing and resolving SSI. The studies appearing below are at the forefront of the efforts to use place-based approaches to determine how students engage SSI through more nuanced and contextualized ways.

Herman (2018) and Herman et al. (2019) investigated 60 secondary students who experienced a week long field SSI instruction focused on the local SSI of wolf reintroduction in Yellowstone National Park. The SSI instruction involved interactions with wildlife ecologists who were involved with the Yellowstone wolf reintroduction and subsequent research and outreach efforts pertaining to the wolves' impact on the Yellowstone ecological and human communities. These interactions, which often took place in natural areas where competing ecology groups were actively researching the presence of a wolf mediated trophic cascade, served as a contextual basis on which to address abstract themes such as the limitations to the top down trophic cascade theory, how ecologists' methods do not fit a set procedure, and the diverse cultural and moral perspectives about wolf extirpation and preservation. Through that instruction the students' trophic cascade science explanations and NOS views became significantly more informed, sophisticated and contextualized. Furthermore, the students' developed significantly higher levels of nuanced and targeted compassion toward people and nature impacted by SSI and a willingness to resolve those SSI. Herman (2018) also showed that the students who, after the place-based SSI instruction, donated their participant incentive to a Yellowstone environmental organization demonstrated significantly higher degrees of contextualized NOS understanding, compassion for others impacted by SSI, and willingness to resolve SSI than their non-donating peers. Thus, this study appeared to be an initial effort in the SSI field to link NOS and affective variables to an enacted decision with concrete experienced sacrifice. Future directions for the SSI field proposed from this study include determining the extent that the varying characteristics of learners, the environment and stakeholders they interact with, and the personal and communal demands of SSI resolution (e.g., monetary, advocacy, etc.) impact aspects of SSI engagement to include NOS learning, perspective taking, development of compassion for others and decision-making.

In an attempt to build upon previous work (e.g., Sadler \& Zeidler, 2005) and provide a more nuanced framework for emotive socioscientific reasoning, which Herman, Zeidler, and Newton (2018) recognized plays an important role for socioscientific decision-making, they investigated the ways in which 24 post-secondary students from diverse academic majors experienced 10 days of place-based SSI instruction in Yellowstone National Park as part of a six-week capstone course focused on environmental and social issues. The SSI instruction is described and followed the design elements profiled in Herman et al. (2018) and focused on the themes of sustainability, socio-moral compassion, and the affordances and limitations of science for socioscientific resolution. Throughout the place-based SSI instruction, the students had first-hand experiences with diverse stakeholders (e.g., ranchers, biologists, and Native Americans) that expressed their deep-seated perspectives about Yellowstone issues such as brucellosis in bison, elk herd management, and wolf reintroduction. The culmination of the place-based SSI instruction involved the students in a town-hall style council meeting at a Gardiner, MT bar and grill where they assumed the roles of the stakeholders encountered in Yellowstone and were required 
to propose, debate, and defend an evidence-based resolution to wolf hunting quotas in front of their peers who played the role of a deliberating federal panel. After this place-based SSI instruction, the 24 students expressed more nuanced and intense forms of emotive reasoning, and while doing so explicitly considered the perspectives of the stakeholders they had encountered in Yellowstone. Based on the students' expressions, Herman, Zeidler, and Newton (2018) constructed a empirically situated framework of qualitative emotive reasoning taxonomies that people may experience when encountering others coping with SSI, ranging from apathy and general caring to regulated (e.g., value judgments) and more visceral forms of empathy that entail moral and justice considerations (e.g., righteous indignation). Herman and colleagues proposed this framework in hopes of motivating others in the field to conduct larger scale studies that compare how distinct educational (e.g., classroom versus place-based and informal) and sociocultural contexts differentially influence emotive responses and decisions when resolving SSI.

\section{Conclusions: the educational significance of new directions in SSI research}

The importance of SSI research and practice in contemporary and future science education is highlighted by the need for student engagement with the world in which they reside, and will transform and shape it for generations to come. From a progressive philosophy, engagement must reside in authentic purpose and not by forced external demands. Coercion to achieve external rewards is always less preferable and less effective compared to decisions made from emotive passions to spread virtue. The synergistic effect of emotive factors in the learning of science content and its facilitative effect on decision-making of SSI has been well documented in the literature (Jack, Lin, \& Yore, 2014; Jho, Yoon, \& Kim, 2014). Related empirical research demonstrates that engagement in SSI contexts, both formal and informal, resonates with students' enjoyment of developing a sense of personal ethics (Tsai \& Jack, 2019) as they consider multiple perspectives from different sources. Thinking ethically, so it seems, allows for bridges to be built between science and non-science areas of study, and subsequently between and among students and the social, material, organic and physical world in which they dwell.

That the moral dimensions of students are directly impacted by the moral elements contained within the SSI framework should not be surprising. For example, the five dimensions of SSR (found in Sadler and colleagues work above) provide the reasoning structures necessary for the complex nature of SSI and allow for the fair and equitable evidence-based decisions that are rendered. We have further uncovered that Socioscientific Perspective Taking (SSPT) (found in Kahn and Colleagues above) is a particularly viable construct because of the recognition of the foundational conditions that must be present to apply it to varied SSI contexts. Those three conditions (Engagement, Etic to Emic Shift, Moral Context) allow for the full application of SSPT to a plethora of educative SSI experiences ranging from classroom discussions, to town-hall debates, to place-based environmental scenarios. Finally, we call attention to the significance of place-based and informal SSI (found in Herman and colleagues above) that is critical when topics seem too far removed or detached from the repertoire of students' everyday experiences. While many topics can be engaging in formal classroom settings, there are certainly particular topics where students can greatly benefit from the kind of immersive experience found only when they can situate themselves in authentic contexts. Such immersive experiences serve as a platform for the development of socio-cultural awareness and moral sensitivity. We are optimistic that these new trends in SSI research and practice will lead to the development of new understandings and the refinement of pedagogical strategies to help shape the robustness of the SSI framework.

Finally, we wish to consider how these current trends discussed above (Socioscientific Issues and the Central Role of Socioscientific Reasoning, Socioscientific Issues and the Primacy of Socioscientific Perspective Taking, and Socioscientific Issues and the Importance of Informal and Place-Based Contexts) may be associated with using SSI in different cultural contexts. We are aware of the fact that all educationally significant SSI are controversial, but not all controversial issues (e.g., capital punishment) constitute significant SSI because they lack underpinning scientific components. Furthermore, we also recognize that the moral tension surrounding SSI is socioculturally bounded. For example, in many conservative religious parts of the US, evolution, natural selection and hence antibiotic resistant bacteria may be controversial. However, among evolutionary scientists and epidemiologists, these topics would not typically be considered controversial in that there is virtually no disagreement about the general underlying mechanisms of evolution as a unified concept. More broadly, other issues that may connect to cloning, climate change or nuclear power, for example, may be rather "neutral" in some parts of the globe, but not others. Since SSI is embedded in a sociocultural view of education, the degree of educational significance is no doubt tied to the prevailing norms of a particular context relative to that SSI. Hence, future research that informs pedagogy in significant ways awaits further exploration. It is interesting to note that past cross-cultural research (Zeidler et al., 2013) has found a high degree of epistemological congruity across cultures (Jamaica, South Africa, Sweden, Taiwan, and the United States) in the context of the 
allocation of scarce medical resources revealing common themes that included fairness; pragmatism; emotive reasoning, utility; and theological issues. However, there were also statistically significant differences regarding the ability to raise scientifically relevant questions among countries. These results help to shed light on the nuances of the themes discussed in this article and the need for better understanding contextual differences of morality as it relates to SSI and culture.

\section{Abbreviations \\ CAS: Computer automated scoring; NOS: Nature of Science; \\ QuASSR: Quantitative Assessment of Socio-Scientific Reasoning; \\ SSI: Socioscientific Issues; SSPT: Socioscientific Perspective Taking; \\ SSR: Socioscientific Reasoning}

\section{Acknowledgements}

Not applicable.

\section{Authors' contributions}

DLZ contributed (equally) to the conceptualizing and writing of this manuscript. $\mathrm{BCH}$ contributed (equally) to the conceptualizing and writing of this manuscript. TDS contributed (equally) to the conceptualizing and writing of this manuscript. All authors read and approved the final manuscript.

\section{Funding}

Not applicable.

\section{Availability of data and materials}

Not applicable)

\section{Competing interests}

The authors declare that they have no competing interests.

\section{Author details}

${ }^{1}$ Department of Teacher Education, College of Education, University of South Florida, Tampa, Florida, USA. ${ }^{2}$ Department of Teaching, Learning and Culture, College of Education and Human Development, Department of Biology, College of Science, Texas A \& M University, College Station, Texas, USA. ${ }^{3}$ School of Education, University of North Carolina-Chapel Hill, Chapel Hill, North Carolina, USA.

Received: 18 April 2019 Accepted: 12 June 2019

Published online: 28 November 2019

\section{References}

Batson, C. D. (2009). These things called empathy. In J. Decety, \& W. Ickes (Eds.), The social neuroscience of empathy. Cambridge: MIT Press.

Bencze, J.L., Pouliot, C., Pedretti, E. Simonneaux, L., Simonneaux, J. \& Zeidler, D.L. (In Press). SAQ, SSI \& STSE education: Defending and extending 'Science-inContext.' Cultural Studies in Science Education.

Berkowitz, M.W. (1997). The complete moral person: Anatomy and formation. In DuBois, J.M. (Ed.), Moral issues in psychology: Personalist contributions to selected problems. New York: University Press of America, Inc.

Bossér, U., \& Lindahl, M. (2019). Students positioning in the classroom: A study of teacher-student interactions in a socioscientific issue context. Research in Science Education, 49(2), 371-390.

Elgström, O., \& Hellstenius, M. (2011). Curriculum debate and policy change. Journal of Curriculum Studies, 43, 717-738.

Fowler, S., Zeidler, D. L., \& Sadler, T. D. (2009). Moral sensitivity in the context of socio-scientific issues in high school science students. International Journal of Science Education, 31, 279-296.

Gifford, R., \& Nilsson, A. (2014). Personal and social factors that influence proenvironmental concern and behaviour: A review. International Journal of Psychology, 49(3), 141-157.

Gruenewald, D. A., \& Smith, G. A. (Eds.) (2008). Place-based education in the global age: Local diversity. New York: Erlbaum.
Herman, B. C. (2015). The influence of global warming science views and sociocultural factors on willingness to mitigate global warming. Science Education, 1(1), 1-38.

Herman, B. C. (2018). Students' environmental NOS views, compassion, intent, and action: Impact of place-based socioscientific issues instruction. Journal of Research in Science Teaching, 55(4), 600-638.

Herman, B. C., Owens, D. C., Oertli, R. T., Zangori, L. A., \& Newton, M. H. (2019). Exploring the complexity of students' scientific explanations and associated NOS views within a place-based socioscientific issue context. Science and Education On-line first version retrieved 03/15/2019 from: https://doi.org/10. 1007/s11191-019-00034-4.

Herman, B. C., Sadler, T. D., Zeidler, D. L., \& Newton, M. H. (2018). A socioscientific issues approach to environmental education. In G. Reis, \& J. Scott (Eds.), International perspectives on the theory and practice of environmental education: A reader, Environmental discourses in science education (vol. 3). Cham: Springer.

Herman, B. C., Zeidler, D. L., \& Newton, M. H. (2018). Emotive reasoning through place-based environmental socioscientific issues. Research in Science Education On-line first version retrieved 03/15/2019 from: https://doi.org/10. 1007/s11165-018-9764-1.

Hoffman, M. L. (2000). Empathy and moral development: Implications for caring and justice. Cambridge: Cambridge University Press.

Hoffman, M. L. (2008). Empathy and prosocial behavior. In M. Lewis, J. HavilandJones, \& L. Barrett (Eds.), Handbook of emotions, (pp. 440-455). New York: Guilford.

Jack, B. M., Lin, H.-S., \& Yore, L. D. (2014). The synergistic effect of affective factors on student learning outcomes. Journal of Research in Science Teaching, 51(8), 1084-1101.

Jho, H., Yoon, H.-G., \& Kim, M. (2014). The relationship of science knowledge, attitude and decision making on socio-scientific issues. Science \& Education, 23(5), 1131-1151

Kahn, S., \& Zeidler, D. L. (2016). Using our heads and HARTSS*: Developing perspective-taking skills for socioscientific reasoning (*humanities, arts, and social sciences). Journal of Science Teacher Education, 27(3), 261-281.

Kahn, S., \& Zeidler, D. L. (2017). A case for the use of conceptual analysis in science education research. Journal of Research in Science Teaching, 54(4), 538-551.

Kahn, S., \& Zeidler, D.L. (2019). A conceptual analysis of perspective taking: Positioning a tangled construct within science education and beyond. Science \& Education, 28, 605-638.

Khishfe, R. (2012). Nature of science and decision-making. International Journal of Science Education, 34(1), 67-100.

Kinslow, A. T. (2018). The development and implementation of a heuristic for teaching reflective scientific skepticism within a socio-scientific issue instructional framework. Unpublished dissertation. Columbia: University of Missouri.

Kinslow, A. T., Sadler, T. D., \& Nguyen, H. T. (2019). Socio-scientific reasoning and environmental literacy in a field-based ecology class. Environmental Education Research, 1-23 On-line first version retrieved 03/15/2019 from: https://doi. org/10.1080/13504622.2018.1442418.

Konrath, S., O'Brien, E., \& Hsing, C. (2011). Changes in dispositional empathy in American college students over time: A meta-analysis. Personality and Social Psychology Review, 15(2), 180-198.

Kormos, C., \& Gifford, R. (2014). The validity of self-report measures of proenvironmental behavior: A metaanalytic review. Journal of Environmental Psychology, 40, 359-371.

Lee, H., Kyunghee, C., Kim, S., Jungsook, Y., Krajcik, J. S., Herman, B. C., \& Zeidler, D. L. (2013). Socioscientific issues as a vehicle for promoting character and values as global citizens. International Journal of Science Education, 35(12), 2079-2113.

Lindahl, M. G., Folkesson, A.-M., \& Zeidler, D. L. (2019). Students' recognition of educational demands in the context of a socioscientific issues curriculum. Journal of Research in Science Teaching. (Early view. https://doi.org/10.1002/tea.2154.

Martin, J., Sokol, B. W., \& Elfers, T. (2008). Taking and coordinating perspectives: From prereflective interactivity, through reflective intersubjectivity, to metareflective sociality. Human Development, 51, 294-317. https://doi.org/10. 1159/000170892.

National Research Council (2012). A Framework for K-12 Science Education: Practices, Crosscutting Concepts, and Core Ideas. In Committee on a conceptual framework for new K-12 science education standards. Board on science education, division of behavioral and social sciences and education. Washington, DC: The National Academies Press.

NGSS Lead States (2013). Next Generation Science Standards: For States, By States. Washington, DC: The National Academies Press. 
Romine, W. L., Sadler, T. D., \& Kinslow, A. T. (2017). Assessment of scientific literacy: Development and validation of the quantitative assessment of socio-scientific reasoning (QuASSR). Journal of Research in Science Teaching, 54, 274-295. https://doi.org/10.1002/tea.21368.

Sadler, T. D. (2009). Situated learning in science education: Socio-scientific issues as contexts for practice. Studies in Science Education, 45(1), 1-42.

Sadler, T. D., Barab, S., \& Scott, B. (2007). What do students gain by engaging in socioscientific inquiry? Research in Science Education, 37(4), 371-391.

Sadler, T. D., Klosterman, M. L., \& Topcu, M. S. (2011). Learning science content and socio-scientific reasoning through classroom explorations of global climate change. In T. D. Sadler (Ed.), Socio-scientific issues in the classroom: Teaching, learning and research, (pp. 45-77). Dordrecht: Springer.

Sadler, T. D., \& Zeidler, D. L. (2005). Patterns of informal reasoning in the context of socioscientific decision making. Journal of Research in Science Teaching, 42(1), 112-138.

Selman, R. L. (1971). Taking another's perspective: Role-taking development in early childhood. Child Development, 42, 1721-1734. https://doi.org/10.2307/ 1127580

Selman, R. L. (1977). A structural-developmental model of social cognition: Implications for intervention research. The Counseling Psychologist, 6(4), 3-6. https://doi.org/10.1177/001100007700600403.

Semken, S., \& Freeman, C. B. (2008). Sense of place in the practice and assessment of place-based science teaching. Science Education, 92(2), 1042-1057.

Simonneaux, L., \& Simonneaux, J. (2009). Socio-scientific reasoning influenced by identities. Cultural Studies in Science Education, 4(3), 705-711.

Sobel, D. (2004). Place-based education: Connecting classrooms and communities. Great Barrington: The Orion Society.

Tsai, C.-Y., \& Jack, B. M. (2019). Antecedent factors influencing ethic-related social and socio-scientific learning enjoyment. International Journal of Science Education On-line first version retrieved 03/29/2019 from: https://doi.org/10. 1080/09500693.2019.1595215.

Venville, G. J., \& Dawson, V. M. (2010). The impact of a classroom intervention on grade 10 students' argumentation skills, informal reasoning, and conceptual understanding of science. Journal of Research in Science Teaching, 47(8), 952-977.

Womack, A. J. (2019). Development and multi-tiered analysis of a socio-scientific reasoning assessment. In Application of computer automated scoring and Rasch analysis. University of Missouri Unpublished dissertation.

Zeidler, D., Herman, B. C., Ruzek, M., Linder, A., \& Lin, S. S. (2013). Cross-cultural epistemological orientations to socioscientific issues. Journal of Research in Science Teaching, 50(3), 251-283.

Zeidler, D. L. (2003). The role of moral reasoning on socioscientific issues and discourse in science education. The Netherlands: Kluwer Academic Press.

Zeidler, D. L. (2014). Socioscientific issues as a curriculum emphasis: Theory, research and practice. In N. G. Lederman, \& S. K. Abell (Eds.), Handbook of research on science education, volume II, (pp. 697-726). New York: Routledge.

Zeidler, D. L. (2016). STEM education: A deficit framework for the $21^{\text {st }}$ century? A sociocultural socioscientific response. Cultural Studies of Science Education 11(1), 11-26.

Zeidler, D. L., Herman, B. C., Clough, M. P., Olson, J. K., Kahn, S., \& Newton, M. (2016). Humanitas emptor: Reconsidering recent trends and policy in science teacher education. Journal of Science Teacher Education, 25(5), 465-476.

Zeidler, D. L., \& Kahn, S. (2014). It's debatable: Using Socioscientific issues to develop scientific literacy, K-12. Arlington: National Science Teachers Association Press.

Zeidler, D. L., Sadler, T. D., Applebaum, S., \& Callahan, B. E. (2009). Advancing reflective judgment through socio-scientific issues. Journal of Research in Science Teaching, 46, 74-101.

Zeidler, D. L., Walker, K. A., Ackett, W. A., \& Simmons, M. L. (2002). Tangled up in views: Beliefs in the nature of science and responses to socio-scientific dilemmas. Science Education, 86, 343-367.

\section{Publisher's Note}

Springer Nature remains neutral with regard to jurisdictional claims in published maps and institutional affiliations.

\section{Submit your manuscript to a SpringerOpen ${ }^{\circ}$ journal and benefit from:}

- Convenient online submission

- Rigorous peer review

- Open access: articles freely available online

- High visibility within the field

- Retaining the copyright to your article

Submit your next manuscript at $\boldsymbol{\nabla}$ springeropen.com 